\title{
Marihuana: desengaño y resignificación
}

\section{Marihuana: deception and resignification}

\author{
Quien ha conocido el Sistema, ha encontrado un cadáver \\ $y$ quien ha encontrado un cadáver, de él no es digno el Sistema \\ Jesús de Nazaret, evangelio de Santo Tomás \\ Andrey Alexis Peña Osorio \\ Estudiante de último semestre de psicología \\ Universidad Surcolombiana
}

Escribo el presente ensayo ${ }^{1}$ con la honesta y fundamentada intención de contribuir, mediante la experiencia personal, el ejercicio filosófico y el empleo de argumentos de las ciencias naturales y sociales, en la demolición de las creencias prejuiciosas y descalificadoras sobre la planta de marihuana y sus consumidores. Pues a partir de estas creencias los usuarios de la planta nos vemos rechazados en el plano social y familiar, matoneados por docentes y pares al punto de la expulsión de las instituciones educativas, incluso nos vemos seriamente expuestos a ser excluidos en el área laboral, dimensión fundamental para el equilibrio psicológico de una persona.

Me refiero a creencias tales como que "la marihuana produce enfermedades orgánicas y psicológicas", que "impide estudiar"y que "el consumidor de marihuana es propenso a desarrollar comportamientos irresponsables, violentos y delictivos". Lo anterior lleva a su vez la idea implícita de que las sustancias psicoactivas permitidas legalmente y aceptadas en sociedad, como el alcohol, el tabaco y la cafeína, no son peligrosas para la salud o lo son en menor grado, supuesto que por ser erróneo genera estilos de vida equivocados. Es claro entonces que el propósito de este texto será cooperar en el derribamiento de las ideas que patologizan y criminalizan a la planta y al usuario del cannabis, sin más sustento que los rumores culturales que deambulan entre la familia, la comunidad, la escuela y los medios de información.

En contravía de las creencias infundadas sobre la marihuana, describiré primero los aspectos sociohistóricos que subyacen al origen de este imaginario, entendido como lmaginario social instituido, el cual, según (Castoriadis, 2001), es el conjunto de significaciones o representaciones institucionalizadas que regulan la vida de los hombres y permanecen en la sociedad hasta que un cambio histórico lento o una nueva creación masiva venga a modificarlas o a reemplazarlas radicalmente por otras formas o significaciones. Es decir, en la primera parte del texto describiré cómo este imaginario peyorativo se instaló -o se instituyó, en términos de Castoriadis (2001)- en el pensamiento de las comunidades y las familias occidentales, a partir de las campañas de prevención que se implementaron en las escuelas y en los medios de información, como eco obligatorio, por parte de los países firmantes de las legislaciones sobre drogas, establecidas por la Organización de las Naciones Unidas (ONU) en la segunda mitad del siglo XX.

En segundo lugar emplearé la información que la farmacología y la epidemiología, seria y confiable incluso oficial-, ofrecen sobre las sustancias psicoactivas, esto con el propósito de que el lector conozca cómo actúan las drogas en el cuerpo y con qué enfermedades o alteraciones físicas, psicológicas y comportamentales están relacionadas, pues así él podrá sopesar cuáles drogas son las más dañinas y, al mismo tiempo, preguntarse si la última legislación global sobre sustancias psicotrópicas (Convenio sobre Sustancias Sicotrópicas de la ONU, 1971) fue coherente con los criterios de prohibición que estableció en su preámbulo: "la preocupación por" el influjo de las sustancias sobre "la salud física y moral de la humanidad".

Quisiera de una vez darle tratamiento al interrogante de cómo se instalaron las creencias peyorativas en la mente colectiva, sin embargo, es indispensable que el lector conozca cómo se fabricaron estas, antes de que las instalaran en la mente de los ciudadanos acríticos. Los primigenios detractores de la marihuana, para fabricar las creencias, que no para extenderlas, emplearon la técnica del sofisma.

Ésta es una antigua técnica psicológica mediante la cual las élites de cada época han logrado hacer pasar lo bueno por malo, lo falso por veraz y lo deseable por

1 - Para la elaboración de este ensayo conté con la asesoría del profesor Carlos Bolívar Bonilla Baquero 
indeseable, usando para ello dos recursos fundamentales: la patologización y la criminalización de lo que constituye un tropiezo para ellos -sea una persona, una idea, una práctica o una minoría- en su intención de controlar el aparato político, económico y epistémico.

Con el empleo de esta técnica del sofisma la tiranía del momento logró que el pueblo judío despreciara a Jesús y acogiera a Barrabás, se empleó contra Sócrates, un promotor de la autonomía moral, que hicieron ver como corruptor de jóvenes, también sobre los científicos medievales cuando al delegarles la búsqueda de la Verdad al experimento y a la razón, fueron acusados literalmente de aliarse con el diablo y, por lo tanto, perseguidos y condenados a crueles torturas por el oscurantismo catolicista reinante. Célebres son la censura y la persecución que sufrieron científicos como Galileo Galilei o, peor aún, Giordano Bruno, quien fuera conducido literalmente a la hoguera (Benítez, 2011) por el "acto iluso y amenazante" de pretender resolver, de manera autónoma y sin intermediarios, los interrogantes que lo asaltaban en la contemplación nocturna del cosmos insondable.

Y así podría continuar dando ejemplos de las aplicaciones de esta técnica del sofisma en las distintas épocas, dirigida sobre personas y minorías cuyas ideas y prácticas resultan lesivas para el statu quo y el sistema de creencias protegido por la élite de facto; la verdad es que estas personas perseguidas, realmente favorables para el desarrollo ético y científico de la humanidad, terminaron señaladas como una amenaza para la sociedad y, lo peor de todo, es que la sociedad se lo creyó y hasta fue cómplice en su cacería.

Pero que no se alarme la sociedad actual con la perversa decisión del pueblo judío, que si ellos rechazaron a Jesús y aceptaron a Barrabás, aquí y ahora se acepta el alcohol y el tabaco -científicamente más nocivos que la marihuana- y se rechaza la cannabis como si fuera el demonio mismo. Claro, otra analogía aplicable, y que me es permitida por las libertades del genero ensayístico, es que lo mismo sucede cuando en la tarima pública se pone a elegir entre Álvaro Uribe y Carlos Gaviria; es visible a quién acoge nuestra sociedad occidentalizada, como ocurrió en las elecciones presidenciales de 2006, que así evidencia lo parecida que es al pueblo que torturó al profeta esenio, en el suelo que hoy descansa, como diadema sobre la frente de un Rey inmortal, la cúpula mahometana.

Es preciso decir también que desde comienzos del siglo XX esta técnica del sofisma se ha empleado como plataforma para justificar la xenofobia, el racismo y la homofobia -mostrar a indios, negros, judíos, musulmanes y homosexuales como seres sin alma, peligrosos y enfermizos, en una palabra: indeseables-. Hoy, y es el objetivo de este ensayo denunciarlo, la técnica del sofisma esgrime la daga de la criminalización y la patologización sobre la práctica cannábica, la medicina aborigen y las ideologías contrahegemónicas.

No es desconocido para nadie, por ejemplo, cómo desde los medios de información y las escuelas se difama al usuario del cannabis transmitiendo la idea de que éste no se quiere porque consume algo dañino para su cuerpo, que es un vago, un irresponsable, un delincuente $y$, por tanto, constituye parte de una comunidad indeseable para la sociedad.

Ahora, para entrar en materia con mi reflexión crítica sobre las legislaciones más significativas del siglo $\mathrm{XX}$ sobre drogas, quisiera recordar un antecedente histórico de la prohibición de sustancias, directamente vinculado al epistemicidio genocida implementado por la organización católica, en concierto con los reyes europeos, para controlar los pueblos ancestrales de Occidente. Sucedió que aquí, en lo que hoy se llama América, se arrasó con un conjunto de conocimientos y prácticas que no obedecían al método científico, pero que redundaban en la formación de sociedades menos desiguales y disfuncionales que las invasoras. Al respecto De Sousa (2010) comenta:

La identificación de las condiciones epistemológicas permite mostrar la vastísima destrucción de conocimientos propios de los pueblos causada por el colonialismo europeo -lo que llamo epistemicidio- $y$, por otro lado, el hecho de que el fin del colonialismo político no significó el fin del colonialismo en las mentalidades y subjetividades, en la cultura y en la epistemología y que por el contrario terminó reproduciéndose en modo endógeno (p. 8).

Ciertamente, las prácticas de los nativos fueron escandalizadas y literalmente satanizadas (Iriarte, 2002), aunque hoy sea claro para nosotros que lo único malo de tales prácticas -por ejemplo la religiosidad de sus plantas medicinales y espirituales- era que ponían en peligro el rol mediacional de la corporación religiosa europea. Es decir, cuando los europeos entendieron que las plantas permiten tener un vínculo directo con lo divino, temieron que el catolicismo sobrara como medio de encuentro entre el hombre y el mundo espiritual. La respuesta fue tajante: arrasar la episteme indígena, la cual se sustentaba en sus plantas visionarias. Sin embargo, jamás se admitió que la persecución a la botánica sagrada aborigen se debiera al tropiezo que constituía para los fines colonizadores del poder invasor.

De tal forma que el ataque a ciertas plantas precisamente por las formas de pensamiento que surgen a partir del encuentro y la convivencia con ellas: pensamiento autónomo, sensible e intuitivo- no es un capricho del siglo XX sino que tiene una historia dialéctica y sistemática que se remonta a la invasión europea en suelo americano, a finales del siglo XV. Presentado este importante antecedente histórico de la actual prohibición de las plantas psicotrópicas, me doy a la tarea de describir los acontecimientos más significativos del siglo $\mathrm{XX}$, en lo concerniente a las 
campañas prohibitivas de drogas.

La primera legislación global fue la de enero de 1912, el Convenio Internacional del Opio, realizada en la Haya, Países Bajos, el cual se concebía como un "esfuerzo humanitario"; esta primera legislación limitó la producción y consumo de opio, morfina y cocaína para fines médicos y científicos. Empero, la marihuana no es prohibida sino hasta febrero de 1925, en la siguiente Convención del Opio realizada en ginebra, Suiza.

Hoy se pueden leer textos (Del Olmo, 1989) que describen cómo la auténtica motivación de los países vinculados a esta legislación no era la preocupación por el bienestar de la humanidad, sino que realmente eran jalonados por intereses particulares, de orden político y, naturalmente, económicos; esto me remite directamente a una bella frase de Correa y Saldarriaga (2014): "las leyes, disfrazadas de universales y neutrales, son solo instrumentos normativos que esconden intereses concretos y particulares" (p. 162).

Por aquel entonces, la descalificación de la marihuana no era tan severa, puesto que el auténtico proyecto de desprestigio del cannabis se emprende en la década de 1930, encabezada por Harry Anslinger, quien fuera, por estos años, un ferviente conservador y a la vez comisionado de la Oficina Federal de Drogas (FBN, Federal Bureau of Narcotics) de los EE UU. Fue a partir de este personaje que comenzó la auténtica campaña de satanización y desprestigio contra la marihuana, como él mismo lo registrará luego en su libro, escrito en compañía de Will Oursler. ${ }^{2}$

Posterior a estos años de descalificación sobrevendrán otros fenómenos -como la generación beat de los años 50 y la emancipación psicodélico pacifista de los hippies durante los años 60, en parte como reacción ante la guerra de Vietnam- que, sumados a la cruzada difamadora de Anslinger, servirán como pretexto moralista para que los vigilantes de la cultura imperante de aquellos días implanten las legislaciones sobre drogas de 1961 (Convención Única sobre Estupefacientes de la ONU) y la de 1971 (Convenio sobre Sustancias Sicotrópicas de la ONU, enmienda de la legislación de 1961). Colombia se adscribirá a esta política prohibitiva en $1974^{3}$, la cual se consolidará posteriormente con la ley 30 de 1986.

Lo llamativo de estas dos legislaciones -la de 1961 y su enmienda en 1971- era que adoptaban como criterios de prohibición el influjo de las sustancias sobre "la salud física y moral de la humanidad", esto es, abordaron la relación existente entre salud y el uso de sustancias psicotrópicas, lo cual hace suponer que fueron prohibidas las sustancias que constituyen un alto riesgo para la salud física y moral, y que quedaron permitidas las que constituyen un riesgo menor para estas dos esferas.

Ahora, la cuestión inevitable sería resolver si las sustancias prohibidas son realmente más peligrosas que las permitidas, sin embargo, esta cuestión se tratará en la segunda dimensión argumentativa, en la cual emplearé la información que la farmacología y la epidemiología ofrecen sobre las sustancias psicoactivas. Por ahora es preciso describir cómo se han instalado, en la mente de los ciudadanos, los imaginarios descalificadores sobre la marihuana.

Cabe recordar -aunque parezca irrelevante hacerloque es con la convención de 1961 que se impone el término estupefaciente en cuya definición sólo incluyó a las sustancias ilegales mas no a las permitidas; esto dará lugar a que la palabra estupefaciente termine fijándose en el pensamiento colectivo como sinónimo de las sustancias prohibidas, pero no de las legalizadas. Diez años después, en el Convenio Sobre Sustancias Sicotrópicas de 1971 (ONU), no se hablará de estupefaciente sino de sustancia sicotrópica, con la misma definición -es decir, para referirse a las sustancias ilegales-, excluyendo de esta categoría a las sustancias legales.

Así se instalarán en el pensamiento colectivo las palabras estupefaciente y sustancia psicotrópica como sinónimos de las sustancias ilegales, no de las sustancias que quedaron permitidas, como el alcohol, el tabaco o cafeína. Esto mismo ha facilitado la aceptación de tales sustancias, al punto que nadie se inmuta por su consumo y se sigue pensando que al usarlas, no se están consumiendo sustancias psicoactivas, cuando la verdad es que incluso cuando tomamos chocolate estamos consumiendo una de ellas $^{4}$

Cabe decir que la definición que dio la ONU en el convenio de 1971 sobre sustancia sicotrópica, contrasta con la definición que da la OMS sobre el mismo término. Para la OMS - y para la ciencia en general- una sustancia psicotrópica o psicoactiva es cualquiera que tenga sus efectos principales sobre el sistema nervioso central, mientras que para la ONU solo las sustancias ilegales o prohibidas son consideradas psicotrópicas; sin embargo la ONU cree haber sido objetiva con esta definición.

Pues bien, las legislaciones de 1961 y de 1971 ya establecidas -en las cuales queda prohibida la marihuana, mientras que sustancias como el alcohol, el tabaco o la cafeína quedan permitidas- son sucedidas, como cualquier otra política pública, por las campañas pedagógicas que las tratarán de justificar y de afianzar. En este proceso pedagógico

2 - "Los asesinos, la historia de las bandas de narcóticos" (Oursler \& Anslinger, 1961), aquí se puede leer en detalle las estrategias irracionales y antiacadémicas mediante las cuales se desarrolló la campaña difamatoria contra la marihuana.

3 - Ley 13 de 1974, Por medio de la cual se aprueba la "Convención Única sobre Estupefacientes", hecha en Nueva York el 30 de marzo de 1961, y su Protocolo de Modificaciones, hecho en Ginebra el 25 de marzo de 1972.

4 - El chocolate tiene un componente psicoactivo estimulante denominado teobromina, perteneciente, como lo es también la cafeína y la teofilina, al grupo químico de las metilxantinas. 
participan los medios de comunicación -películas, novelas, documentales, revistas, radio, noticieros, propagandas- $y$ las instituciones educativas, estamentos que no cuestionarán la veracidad de lo promulgado en la ONU, sino que terminarán reproduciendo e instituyendo así, en la mente ingenua de cada ciudadano, el imaginario social actual sobre las sustancias prohibidas y las sustancias permitidas.

Ahora bien, no hay que olvidar, por amor a la coherencia y la convivencia, cómo algunos fieros líderes prohibicionistas y moralistas han terminado envueltos en escándalos de corrupción, como el ex presidente de los EE UU Richard Nixon, quien en 1974 , tres años después de su discurso donde declaraba la guerra contra las drogas, anunciaba su dimisión debido a un caso de corrupción hoy bastante célebre: el caso Watergate. Cabe recordar que Nixon, como afirma Gootenberg citado por Gaviria \& Mejía (2011), "concentró su legendaria ira política en la marihuana".

Sin embargo, el mejor ejemplo de la doble moral en la represión contra los usuarios del cannabis, lo constituye el grupo político colombiano de ultraderecha encabezado por Álvaro Uribe Vélez. ¿Cómo es posible que individuos con prontuarios delictivos que relacionan al susodicho ${ }^{5}$ y a su equipo de presos y $\operatorname{convictos}^{6}$ tengan la autoridad de imponer estilos de vida a toda una nación? Cómo no invocar, en este sentido, lo plasmado por Escohotado (2008), cuando documenta los vínculos de la mismísima Casa blanca y la CIA con gánsters del nivel del anticastrista Sicilia Falcón, o las conexiones de G. Bush con el cartel de Medellín.

Un aspecto que no puedo omitir -que además me sorprende por lo irónico- es la hostilidad que recibe la Comunidad Cannábica por parte de algunos partidarios de la izquierda en Colombia, por ejemplo, recuerdo claramente un "congreso de los pueblos" en la Universidad Nacional de Bogotá en el cual percibí cómo, sobre una considerable porción de los participantes, aún operan los imaginarios vulgares sobre la marihuana y sus consumidores.

Las exhorto a ustedes, valientes organizaciones de izquierda, a que comprendan que quienes han descalificado al cannabis y a sus usuarios son los mismos que las han criminalizado a ustedes, esos que diezmaron a la Unión Patriótica. Son aquellos que, como refiere Acebedo (2008), persiguieron en los albores del siglo pasado a librepensantes como Rafael Uribe Uribe con el sofisma de que ser liberal es pecado, e impedían a los crédulos relacionarse con los disidentes liberales, mediante chantajes como el 'dime con quién andas y te diré quién eres', frase que refleja el singular carácter xenófobo y discriminatorio de quien la ideó. ¡Vaya uno a saber en el útero de qué organización se gestó este aforismo! Y así, librepensadores del siglo $\mathrm{XX}$ y librepensadores del siglo XXI somos perseguidos por la misma élite conservadora, incluso por la misma razón: porque somos un tropiezo para su propósito monopolizador del aparato político, económico y epistémico. No es coherente que críticos de izquierda caigan en la trampa del moralismo oligarca, de obedecer a sus intenciones de desprestigiar a la Comunidad Cannábica.

Hasta aquí he tratado dos cosas importantes: la forma como se instalaron los imaginarios descalificadores sobre la marihuana en el pensamiento colectivo y, además, ofrecer documentos -con seguridad que existen muchos más- que revelan cómo las políticas prohibitivas son abanderadas por líderes políticos de mente retorcida, incluso narcotraficantes.

Cabe apuntar, para terminar la primera parte, que Colombia consolida esta política prohibitiva en la ley 30 de $1986^{7}$, la cual experimentó una ligera modificación con profundas consecuencias favorables para la libertades individuales, mediante la sentencia C-221/94 de la Corte Constitucional, cuyo ponente fue el amable erudito Carlos Gaviria, a quien manifiesto $\mathrm{mi}$ más honesto respeto y agradecimiento por su defensa del Estado Social de Derecho. Esta liviana modificación es la que permite el porte y consumo de la dosis personal sin que por ello la persona deba ser sancionada u obligada a internarse en establecimiento médico para recibir tratamiento.

Lo molesto hoy es que este derecho al porte de la dosis personal no se respeta por la autoridad policial, constituyéndose en un cotidiano abuso por parte de los uniformados; además, esta misma ley tiene un limbo jurídico, porque si permite portar marihuana, admite entonces que el ciudadano la consuma, pero no explica en qué lugares, generando continuas confrontaciones entre usuarios y policías. Algo así como: ¿si existen lugares para los fumadores de cigarrillo -porque la ley acepta consumir cigarrillo-, dónde están los lugares indicados para el fumador de cannabis, puesto que la ley en Colombia no solo autoriza portarla sino también consumirla? ¿O permite portarla pero no consumirla? Esto ya no sería un limbo jurídico sino una aberración jurídica: "puedo portar 22 gramos pero consumir ninguno". Pregunto respetuosa y apaciblemente a la Policía, al Congreso de la República y a la Corte Constitucional: ¿Dónde puedo recrearme con mi cigarro de marihuana -como bien pude recrearse el fumador de tabaco en distintos lugares- sin que mis derechos sean atropellados por un civil o un policía?

5 - Gonzalez, G. (4 deJunio, 2014). "Apoyar a Uribe-Zuluaga es cohonestar con el delito". El Espectador. Recuperado de http://www.elespectador.com/noticias/nacional/apoyar-uribe-zuluaga-cohonestar-el-delito-articulo-496509

6 - EL TIEMPO. (19 de abril de 2015). Las batallas perdidas del uribismo en la justicia. El Tiempo. Recuperado de http://www.eltiempo.com/politica/justicia/uribistas-procesados-por-delitos/15593157.

7 - En el capítulo II de la esta ley, específicamente los artículos 10, 11 y 12, es clara la obligación de los medios de información y las instituciones educativas de afianzar y consolidar estas políticas prohibitivas. 
He descrito los aspectos sociohistóricos que subyacen al origen del imaginario social instituido sobre la marihuana, aspectos estrechamente vinculados a las legislaciones establecidas por la ONU y las subsiguientes campañas de prevención a través de medios de información e instituciones educativas, que terminarán afianzando estas legislaciones e instalando en el pensamiento colectivo los imaginarios difamadores sobre la planta. Al mismo tiempo la propaganda consumista exalta las drogas permitidas, las cuales, hoy se sabe, y la institucionalidad científica siempre lo ha sabido, son más perjudiciales para la salud.

Es oportuno abordar ahora la siguiente pregunta: ¿es coherente que la marihuana haya sido prohibida y sustancias como el alcohol, el tabaco y la cafeína hayan sido permitidas? O lo que es lo mismo: ¿está bien que durante medio siglo -y aún hoy- se haya desprestigiado, rechazado y excluido al usuario del cannabis, basados en la idea de que este ha optado por una sustancia más peligrosa que las aceptadas en sociedad, ante las cuales nadie se inmuta?

Esto me obliga a recurrir a la farmacología y a la epidemiología, pues son las autoridades científicas e institucionales -sin embargo estoy convencido de que la experimentación responsable y documentada es un camino igual o más acertado que la institucionalidad científica- para conocer cuál de estas cuatro sustancias es más nociva para la salud física y la salud moral del humano, pues fue sobre estos dos criterios que se asentó la legislación vigente sobre drogas: la de 1961 y su enmienda de 1971.

Como el grado de peligro de una sustancia es determinado por tres criterios: la intensidad del síndrome de abstinencia ${ }^{8}$, las enfermedades con que la sustancia se relaciona y los comportamientos irresponsables, violentos y delictivos a los que da lugar su consumo, será a partir de estas tres pautas que evaluaré -según lo indicado por la farmacología y la epidemiología- cuál de estas cuatro sustancias es la más destructiva para el individuo y para la sociedad.

En cuanto al primer criterio, el síndrome de abstinencia de la marihuana se caracteriza por insomnio, agitación, pérdida del apetito e irritabilidad. Aunque el síndrome de abstinencia de la marihuana presenta los síntomas antes mencionados, éstos no resultan tan preocupantes como los generados por el síndrome de abstinencia alcohólica (Organización Panamericana de la Salud, 1999), caracterizados por hiperactividad autonómica, temblor distal de las manos, insomnio, náuseas o vómitos, ansiedad, alucinaciones visuales, táctiles o auditivas transitorias o ilusiones, agitación psicomotora y crisis convulsivas (Oviedo \& Arboleda, 2006). Incluso se han reportado muertes provocadas por el síndrome de abstinencia alcohólica (Santolaria \& González-Reimers, 2006).

En cuanto al síndrome de abstinencia cafeínico, los síntomas característicos son cefalea, somnolencia, irritabilidad, náuseas, vómitos, entre otros, por lo cual se recomienda reducir gradualmente el consumo de cafeína para no llegar a padecerlos (Osada, Rojas, Vásquez, \& Vega, 2008). En lo referido al síndrome de abstinencia del tabaquismo, caracterizado por cefaleas constantes, mareos, insomnio, aumento del apetito, irritabilidad, ansiedad y frustración, se tiene en cuenta que está relacionado con la rapidez con que disminuyen los niveles de nicotina en sangre (Do Carmo, Andrés-Pueyo, \& López, 2005). Lo contrario pasa con los canabinoides, que no desaparecen fácilmente del torrente sanguíneo ya que por ser lipofílicos se adhieren fácilmente al tejido adiposo, donde se alojan para luego retornar gradualmente al fluido vital (Fundació Institut Catalá de Farmacologi, 2015); este aspecto particular de la farmacocinética de los canabinoides parece explicar por qué el síndrome de abstinencia de la marihuana no es tan problemático como el generado por el alcohol o la nicotina.

Es claro cómo en este primer criterio la marihuana es la sustancia que sale mejor librada. Esta variación en el síndrome de abstinencia se va a reflejar en la epidemiología de estas cuatro sustancias, pues mientras más agudo sea el síndrome de abstinencia, mayor es la compulsividad a la sustancia y así mismo el riesgo de lesionar los órganos del cuerpo.

Para abordar el segundo criterio -patologías relacionadas con el consumo habituado de las sustancias-, los estudios indican que el consumo de alcohol está relacionado directamente con enfermedades gastrointestinales (hepatitis alcohólica, cirrosis hepática, pancreatitis aguda y síndrome de malabsorción), enfermedades cardiovasculares, miopatía alcohólica, pelagra y cáncer gástrico (Mosquera \& Menéndez, 2006). En cuanto a la marihuana, parece que persiste la fábula de la psicosis, pues cada vez que se investiga la relación entre consumo crónico de marihuana y enfermedad, los documentos se centran en la psicosis, particularmente la esquizofrenia. Parece que no existen más entidades nosológicas con las cuales se relacione la marihuana.

Debo reconocer que soy diagnosticado como esquizofrénico y como tal tengo la autoridad subjetiva -y el deber ético, además- para hablar de esta relación: pienso que la marihuana no es conveniente durante el brote psicótico, pero sí un buen medicamento para la

8 - El síndrome de abstinencia es el conjunto de síntomas psicofisiológicos (temblor, ansiedad, náusea, vómitos, insomnio, trastornos digestivos y otros más graves que incluyen crisis convulsivas, paranoia y alucinaciones visuales, auditivas y táctiles) que aparecen horas o días después del cese del consumo cotidiano de una sustancia, síntomas que motivan al consumidor a reincidir en el hábito. Es válido pensar que este síndrome juega un papel trascendental en la compulsividad.

9 - Los canabinoides son las moléculas que provocan los efectos notorios de la marihuana (sensación de bienestar, el aumento de la actividad reflexiva y creativa, la analgesia, sensación de hambre y sueño,), tales como el tetrahidrocannabinol (THC), el canabidiol (CBD) y el canabinol (CBN) aunque existen otros, pero menos estudiados que estos tres. 
fase posterior; me atrevo a afirmar incluso, basado en el principio de falsabilidad ${ }^{10}$, que aquella idea de que la marihuana vuelve loco a todo aquel que la emplea es completamente equivocada, pues para que esta idea patologizante de la marihuana tuviese fuerza empírica, todo el que fume marihuana tendría que desarrollar la psicosis, evento que, estadísticamente, es bastante irreal. Además, no todos los que desarrollan esquizofrenia tienen antecedentes de consumo de cannabis (Tamayo, 1998), lo cual indica que la relación entre marihuana y esquizofrenia está lejos de ser una relación causal. O como diría (Ascolani, 2014) "si hubiera una relación causal, deberían haber aumentado las psicosis durante la irrupción masiva del cannabis en Occidente durante los años $60 \mathrm{~s}$ y $70 \mathrm{~s}$, y de manera constante, acompañando la tendencia del consumo, lo que no ha ocurrido" (p. 57).

En cuanto a mi experiencia con la esquizofrenia, debo compartir con ustedes, estimados lectores, que esta es una condición -caracterizada por un desorden sensoperceptivo, mnémico, emocional e interpretativo- que provoca un estado de despersonalización que conduce al sujeto casi que inexorablemente a la exploración, continua y angustiosa, de su dimensión existencial, la cual debería tener acompañamiento de un psicólogo existencial y/o transpersonal, un taita legítimo y un psiquiatra que ojalá tenga apertura epistemológica para interactuar respetuosamente con el taita o chamán. Este impulso de exploración existencial impide que el sujeto atienda a su dimensión material e interpersonal durante algunos meses -yo experimenté un ensimismamiento explorativo que me hizo disfuncional durante un año y medio aproximadamente-, lo cual provoca que la sociedad lo conciba como un ser disfuncional, disfuncionalidad de la que él también se percata, lo cual le resulta agobiante y contraproducente para su recuperación. Desde este punto de vista la esquizofrenia sería vista como una enfermedad puesto que es "incapacitante", sobre todo en un contexto como el occidental en el que los afanes del mercado y los paradigmas de la competitividad no dan espacio a la actividad reflexiva y filosófica sobre el asombroso descubrimiento de Existir.

Diferente lectura se hace desde la perspectiva chamánica -también en la psicología transpersonalque concibe este estado cognitivo como una oportunidad para que el sujeto conozca las imperceptibles dinámicas ambientales, sociales e internas que determinan su estado biológico, su sentir, pensar y actuar, en una palabra: su presente. Es decir, la perspectiva chamánica concibe la psicosis como un estado iniciático, que conduce al sujeto a convertirse en un conocedor de los engranajes íntimos y primarios que movilizan al comportamiento de la Naturaleza y del Humano, tanto el adaptativo como el desadaptativo. Un estado psíquico privilegiado que podría conducir al sujeto a convertirse en un catador de la Realidad, en un Ojo Cósmico... en un Testigo del Universo.

Estoy convencido de que si el mundo civilizado empleara la botánica milenaria académicamente -una especie de sincretismo entre el chamanismo y la ciencia occidental, especialmente áreas como la medicina, la psicología y la física- tendríamos una sociedad menos desajustada y más diestra para abordar los fenómenos de naturaleza ambiental, social, biológica y psíquica.

Para continuar con la epidemiología, debo mencionar que el cigarrillo se encuentra directamente relacionado con enfermedades del sistema circulatorio y respiratorio; por ejemplo enfermedad isquémica del corazón, enfermedad cerebrovascular y cáncer de pulmón, bronquios y tráquea (Kuri, González, Hoy, \& Cortés, 2006). Por lo que respecta a la cafeína, es una sustancia que al metabolizarse se convierte en ácido úrico (Mosquera, 2013), lo cual la convierte en una sustancia peligrosa para personas con enfermedades vinculadas a altos niveles de ácido úrico. Además la cafeína, por estimular la producción de ácido gástrico, resulta venenosa para las personas con úlcera gástrica. Algo que debo añadir sobre la cafeína, contenida en bebidas energizantes como el controvertido Red Bull, es que se ha relacionado con cuatro muertes: un irlandés en el 2000 y tres suecos en 2001 (Pardo, Alvarez, Barral, \& Farré, 2007).

A estos datos les puedo imprimir, a manera de sello, los resultados del informe epidemiológico global y oficial (Organización Mundial de la Salud, 2005) que relaciona las drogas con la carga total de morbilidad. Este afirma que el $8,9 \%$ de las enfermedades está relacionado con el consumo de sustancias psicotrópicas, distribuido de la siguiente manera: 4,1\% relacionadas con alcohol, $4 \%$ relacionadas con tabaco y, atención a esto, sólo el $0,8 \%$ están relacionadas con todas las sustancias ilegales. Mi pregunta es: ¿cuánto le corresponde a la marihuana de este $0,8 \%$ ?

Es evidente que la salud -esa instancia sagrada de la vida- se ve más torpedeada por las drogas legales y aceptadas en sociedad que por la marihuana, por lo menos si comparamos a la marihuana con el alcohol y el tabaco. Entonces, qué tan cierto es que la ONU prohibió las sustancias más peligrosas para la salud. La verdad esto nunca sucedió, esta legislación no ha sido otra cosa que una de las últimas megamanifestaciones de la técnica del sofisma, aplicada y orientada a patologizar y a criminalizar las plantas sagradas y las cosmovisiones ancestrales que cobraron auge a mediados del siglo pasado.

10 - El principio de falsabilidad de Popper constituye un ataque al inductivismo, según este último, de la observación de algunos casos se pueden producir enunciados científicos empíricos generales. El epistemólogo austríaco defiende que no es posible verificar dichos enunciados y que, a cambio, el criterio científico para mantener o refutar una teoría es contrastando falsando- sus principales afirmaciones con un contraejemplo. Si 
En cuanto al tercer criterio, la relación de estas cuatro sustancias con comportamientos irresponsables, violentos y delictivos, tampoco existe discusión en el ámbito de la estadística nacional (Gobierno de Colombia, 2010) y de otros países como Argentina (Observatorio Argentino de Drogas, 2009): la sustancia que más está involucrada con los comportamientos indeseables universalmente (violencia y delito) es el alcohol, muy por encima de la marihuana.

¿Por qué razón, entonces, son los usuarios del cannabis los que deben portar el estigma de viciosos y peligrosos? Esto no tiene soporte empírico, por lo cual debo advertir que es solo una falacia detractora contra el cannabis y sus usuarios. Incluso no es desconocido para nadie cómo es el alcohol la sustancia más presente en el ausentismo laboral, lo cual se puede reconocer como un auténtico comportamiento irresponsable. Ahora bien ¿cuántas personas deben sufrir hoy los estragos de los conductores ebrios?

Luego de evaluar las cuatro sustancias sobre estos tres criterios, es evidente que la sustancia que menos debería preocupar a los ciudadanos es la marihuana. Esto no quiere decir que a partir de esta información propongo que se fume marihuana, sino que los detractores comprendan lo ridículo que representa para un cannábico que le ofrezcan "ayuda", pues no somos nosotros los que necesitamos auxilio; si algo nos quieren ofrecer, que sea respeto a nuestra libre y sana elección, sobre todo que dejen de castigar nuestra inofensiva práctica con difamación, rechazo y exclusión. Aquí debo enaltecer al usuario del cannabis por soportar dos cargas simultáneas: la de la vida y la del estigma que hace doblemente difícil la realización de su proyecto de vida; ¿quién puede poner en duda que al cannábico no se le dan la mismas oportunidades que a los obedientes de los paradigmas hegemónicos morales, axiológicos e ideológicos?

También me parecería irracional que se llegara a pensar en prohibir el alcohol por los graves problemas biológicos y sociales con que se relaciona. La historia nos ha enseñado lo contraproducente que resultó para los Estados Unidos la prohibición del alcohol ${ }^{11}$.

Ahora bien, si caducó la prohibición del alcohol por los daños sociales que representó -a pesar los problemas comportamentales y de salud que produce el consumo habituado de este psicoactivo- por qué no caduca la prohibición de la marihuana entendiendo que el estatus de ilegal de la planta también ha generado nefastos acontecimientos de violencia entre los narcotraficantes que compiten por monopolizar el producto, recordando que las fuerzas del estado no han sido ajenas a estos intereses oscuros.
La marihuana no se legaliza ${ }^{12}$-esta es mi explicación y creo que en ella coincide todo pensamiento sensato y coherente- porque esta nueva condición jurídica de la planta perjudicaría serios intereses del grupo dominante, intereses que abarcan lo económico, lo cultural y, naturalmente, lo político, dadas las propiedades medicinales, industriales y recreativoreflexivas del cannabis.

No puedo dejar de mencionar un factor determinante que desobliga a los círculos del poder a legalizar la planta y es precisamente, parafraseando a Noam Chomsky (1995), que la marihuana no es industrialmente monopolizable -como lo es el tabaco o el alcohol, pues los costos de producción son relativamente mínimos, lo que permite que muchas personas y familias participen de este mercado. $\mathrm{Y}$ claro, entre más aumente la población con independencia laboral y económica, disminuye la población manipulable, pues independencia económica es equivalente a la independencia ideológica, moral y axiológica.

En el plano económico, torpedearía los ingresos desmesurados de la industria farmacéutica, en la medida que algunos medicamentos importantes se van a ver desplazados por el cannabis. También haría tropezar los ingresos de la industria del tabaco y el alcohol, los cuales pueden ser sustituidos por el cannabis como sustancias recreativas. Este es uno de los factores más fuertes que impide la legalización del cannabis: los bloqueos que sigilosamente imponen la industria farmacéutica, alcohólica y tabacalera.

En cuanto a las afectaciones a la cultura, el sistema de creencias será cuestionado por el pensamiento crítico que despierta el cannabis sobre todo en personas universitarias o autodidactas. Y este es el problema para el grupo dominante, que ellos no quieren que sus empresas sean administradas y energizadas por profesionales con pensamiento autónomo, sensible e insumiso, pues la combinación de universidad y cannabis es concebida como peligrosa pólvora para los grupos industriales y empresariales, quienes movidos por este temor obligan a sus lacayos en el ejecutivo y en el legislativo a tomar decisiones hostiles hacia la planta y sus usuarios. Si el uso de la marihuana se naturalizara solo por fuera de las universidades, entre la población marginada de la educación superior, legalizar no sería preocupante para la élite prohibicionista, lo que los aterroriza es que la planta se legitime en las universidades y dé lugar a una generación nueva de profesionales contemplativos, reflexivos, éticos, críticos, propositivos y perseverantes en su proactividad, profesionales que al día de hoy son contaditos.

11 - La ley seca fue aquella que prohibió la producción, distribución, importación, exportación y venta de alcohol en EE UU entre 1919 y 1933 . Los efectos sociales indeseables que produjo - por ejemplo las olas de sangre que bañaron a Norteamérica, debido a la guerra entre bandas criminales motivadas por el control comercial del alcohol, permitieron entender que es más costosa la prohibición que la libertad.

12 - Realmente lo que anhelo no es precisamente la legalización, sino la despenalización, pues legalizar implica la creación de un ordenamiento jurídico que regule la producción, venta y consumo de marihuana, mientras que la despenalización sería simplemente dar vía libre a la producción, venta y consumo de marihuana, tal y como sucede con plantas como el cilantro, la valeriana y el resto. Cualquiera produce, cualquiera vende y cualquiera consume sin necesidad de un permiso estatal. 
Estos rasgos antes mencionados son detestables para los titiriteros que manejan los hilos del poder, pues es inconcebible para ellos que profesionales de este talante administren el aparato industrial e institucional -docentes, agencias científicas, de inteligencia, dirección de presidencia, ministerios, congreso, rama judicial, industria tecnológica, militar y financiera-. Esto explica un poco por qué se trata de extirpar cualquier rastro de cannabis en las universidades.

En cuanto a las afectaciones específicas a los intereses políticos del grupo dominante, para que sus marionetas puedan ocupar la institucionalidad política -logro que requiere el triunfo en las elecciones seudo democráticas y constitucionales- necesitan sufragantes que se traguen todas las falacias que ellos transmiten por sus medios de información. Los universitarios y profesionales marihuaneros no somos ese tipo de sujetos, que por lo demás configuramos una familia, una comunidad: la ecuménica Comunidad Cannábica.

¿Y qué es la Comunidad Cannábica? Es una tribu antigua, heterogénea y cosmopolita que, aunque apuñalada por la técnica del sofisma, convalece, se levanta y camina, llevando a su paso diálogo, ciencia, reflexión, colores, música, malabares y, cómo no, un humito sagrado tan inofensivo como el sahumerio y menos dañino, mucho menos dañino, que el denso humo de ese vehículo, camión o colectivo que, el respetado lector, mira hoy o acaba de emplear.

La Comunidad Cannábica es, en esencia, el ejercicio del libre pensamiento $y$ el triunfo jurídico del cotidianamente violentado derecho al libre desarrollo de la personalidad, es el privilegio de la libre elección del sujeto sin más límites que el derecho del otro. Si he mostrado que la marihuana es mucho menos perjudicial, tanto en lo físico como en lo comportamental, que el tabaco, el alcohol y la cafeína, ¿hasta cuándo perseguirán a nuestra Comunidad?

\section{Referencias bibliográficas}

Acebedo, J. C. (2008). El apetito de la injuria. Neiva, Colombia: Editorial Universidad Surcolombiana.

Ascolani, P. (2014). Marihuana en Argentina: Historia, rendimiento, usos industriales y terapeúticos de la cannabis sativa. Rosario Argentina: Pablo Ascolani.

Benítez, H. (2011). Ensayos sobre ciencia. De Giordano Bruno a Charles Darwin. Santiago de Chile: RIL Editores.
Castoriadis, C. (2001). Figuras de lo pensable. Buenos Aires, Argentina: Fondo de Cultura Económica de Argentina.

Chomsky, N. (1995). Noam Chomsky - Why Marijuana is Illegal and $\mathrm{T} o \mathrm{~b} a \mathrm{c}$ c o i s L e g a l. Ob te $\mathrm{n}$ i d o d e https://www.youtube.com/watch?v=V1 dMfvp96e0

Correa, M. E., \& Saldarriga, D. C. (2014). El epistemicidio indígena latinoamericano, algunas reflexiones desde el pensamiento crítico decolonial. CES DERECHO, 5(2), 154-164.

De Sousa, B. (2010). Descolonizar el saber, reinventar el poder Montevideo, Uruguay: Ediciones Trilce.

Del Olmo, R. (1989). Drogas: distorsiones y realidades. Nueva Sociedad, 81-93.

Do Carmo, J. T., Andrés-Pueyo, A., \& López, E. Á. (2005). La evolución del concepto de tabaquismo. Cadernos de Saúde Pública, 21(4), 999-1005.

Escohotado, A. (1999). Historia general de las drogas. Madrid, España: Espasa.

Fundació Institut Català de Farmacologi. (20 de Noviembre de 2015). Uso terapèutico del cannabis: Farmacología bàsica. Obtenido de http://w3.icf.uab.es/ficf/es/bin/view/Cannabis/FarmacologiaBa sica

Gaviria, A., \& Mejía, D. (2011). Políticas antidrogas en Colombia: éxitos, fracasos y extravíos. Bogotá, Colombia: Universidad Los Andes.

Gobierno de Colombia. (2010). Estudio nacional de consumo de sustancias psicoactivas en adolescentes en conflicto con la ley en Colombia. Instituto Colombiano de Bienestar Familiar, Bogotá.

Iriarte, A. (2002). La razón vulnerada. Neiva, Colombia: Editorial Universidad Surcolombiana.

Kuri, P. A., González, J. F., Hoy, M. J., \& Cortés, M. (2006). Epidemiología del tabaquismo en México. Salud Pública de méxico, s91-s98.

Mosquera, J. T., \& Menéndez, M. C. (2006). ALCOHOL ETíLICO: Un tóxico de alto riesgo para la salud humana socialmente aceptado. Revista de la Facultad de Medicina, 54(1), AAAAA.

Mosquera, O. (2013). Manual de Psicofarmacología. Neiva, Colombia: Orlando Mosquera Villarreal.

Naciones Unidas. (21 de Febrero de 1971). Convenio sobre sustancias s i c otrópicas d e 1971 . Ob t e n i d o d e https://www.unodc.org/pdf/convention_1971_es.pdf

Observatorio Argentino de Drogas. (2009). Estudio nacional sobre consumo de sustancias psicoactivas y su relación con la comisión de delitos en población privada de libertad. República de Argentina.

Organización Mundial de la Salud. (2005). Neurociencia del consumo y dependencia de sustancias psicoactivas. (O. P. Salud, Trad.) Washington, USA

Organización Panamericana de la Salud. (1999). El síndrome de abstinencia de la marihuana. Revista Panamericana de Salud Pública, 5(6), 419 .

Osada, J. E., Rojas, M. O., Vásquez, C. E., \& Vega, J. (2008). Consumo de cafeína en estudiantes de medicina y su coexistencia con sintomatología ansiosa y depresiva. Revista Medica Herediana, 19(3), 102-107.

Oursler, W., \& Anslinger, H. (1961). Los asesinos, la historia de las bandas de narcóticos.

Oviedo, H. C., \& Arboleda, P. L. (2006). Fisiopatología y tratamiento del síndrome de abstinencia de acohol. Universitas Médica, 47(2), 112120 .

Pardo, R., Alvarez, Y., Barral, D., \& Farré, M. (2007). Cafeína: un nutriente, un fármaco, o una droga de abuso. Adicciones, 19(3), $225-238$

Santolaria, F., \& González-Reimers, E. (2006). Mortalidad en el síndrome de abstinencia alcohólica. Anales de Medicina Interna, 23(7), 305-306.

Tamayo, J. M. (1998). Marihuana y esquizofrenia. Revista Colombiana de Psiquiatría, 27(1), 19-31. 